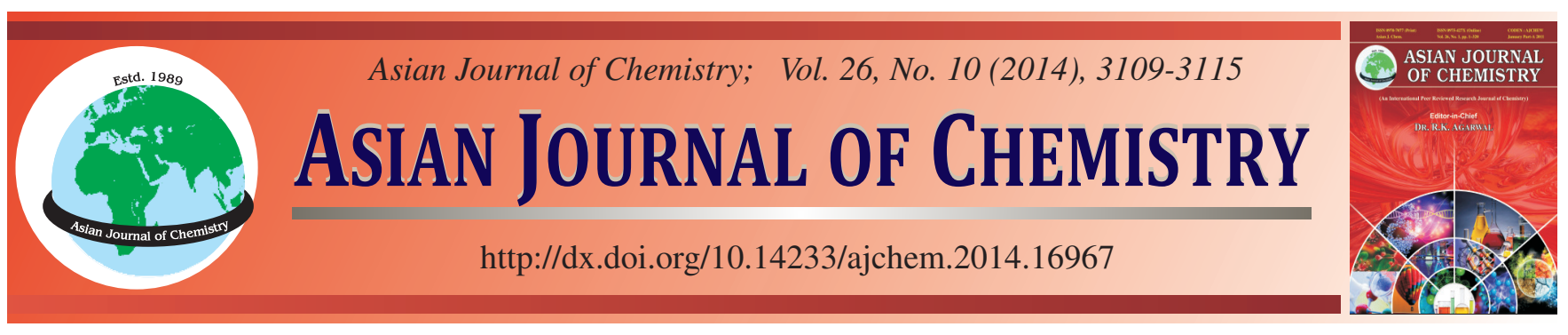

\title{
Prediction and Screening of Biologically Active Compounds in Honeysuckle (Lonicera japonica) by Biopartitioning Micellar Chromatography
}

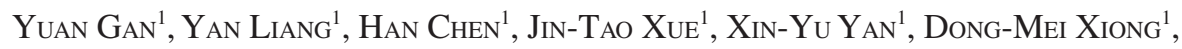

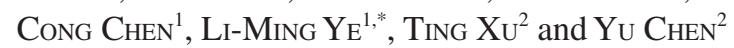

\author{
${ }^{1}$ West China School of Pharmacy, Sichuan University, Chengdu 610041, P.R. China \\ ${ }^{2}$ West China Hospital, Sichuan University, Chengdu 610041, P.R. China \\ *Corresponding author: Fax: +86 288 5502305; Tel: +86 13880747009; E-mail: yeliminglaoshi@126.com; 845464460@qq.com
}

Keywords: Predict and screen, Biopartioning Micellar Chromatography, Honeysuckle (Lonicera japonica), Bioactive compounds.

\section{INTRODUCTION}

Traditional Chinese medicines (TCM) usually contain hundreds or even thousands of components, a single ingredient can be obtained through current means of chemical extraction and isolation. However,before the animal experiments, these single components can not be identified as effective composition. Biopartitioning micellar chromatography (BMC) is a mode of micellar liquid chromatography that uses micellar mobile phases of polioxyethylene (23) laurylether (Brij35) under adequate experimental conditions and can be useful to mimic the drug partitioning process in biological system. It is well-known that drug must permeate a series of sequential biomembranes before reaching a target location where they can express desired pharmacological activity ${ }^{1}$. Based on this physicochemical property, biopartioning micellar chromatography has been developed as a promising tool to predict absorption processes in vivo. It has been demonstrated that the use of retention data obtained in a chromatographic system constituted by micellar mobile phases(Brij35) and C18 reversed stationary phase under adequate experimental conditions is helpful in describing the biological behavior of different kinds of drugs ${ }^{2-10}$. The retention of compounds in this chromato- graphic system depends on its interactions with modified reversed stationary phase and micelles in the mobile phase. These interactions are governed by hydrophobic, electronic and steric properties of compounds. The usefulness of biopartioning micellar chromatography in constructing good models could be attributed to the fact that the characteristics of the biopartioning micellar chromatography (BMC) systems are similar to biological barriers and extracellular fluids ${ }^{11}$. It has been studied comprehensively in the chemical drugs, proteindrug binding and has great significance in guiding the drug design and the development of new drugs ${ }^{12}$. Moreover, biological activity of different oral drugs were studied by our research group ${ }^{13-16}$.

With strong separation ability, biopartioning micellar chromatography is suitable for the screening of bioactive compounds in complex matrices, such as traditional Chinese medicines, etc. However, there is little information available in literature about screening bioactive ingredients of traditional Chinese medicines in conjunction with related chemical drugs of similar curative effects. Honeysuckle is the flowers of Lonicera japonica thunb, which has been planted widely in China. It is one of the most famous traditional Chinese medicine herbs and usually used to cure common cold and 
fever ${ }^{17}$. Honeysuckle contains chlorogenic acid (CA), luteolin7-O-glucoside, volatile oil, flavone, saponins, polysaccharides and polyphenolic compound ${ }^{18}$. As one of the major bioactive compounds rich in honeysuckle, chlorogenic acid can significantly suppress the $\mathrm{N}$-nitrosating reaction and inhibit hepatic glucose 6-phosphatase which is a significant factor in the abnormal diabetic state ${ }^{19}$ and also serves as antioxidant, antiinflammatory, antitumor, antimutagenic and anticarcinogenic agent ${ }^{20-23}$. Honeysuckle has shown a wide spectrum of biological and pharmacological activities such as antibacterial, antiviral $^{24}$, antioxidant ${ }^{25}$.

In this work, an integration approach of biopartioning micellar chromatography with mathematical analysis was established and applied for the prediction and screening of bioactive components in honeysuckle extracts. The models were established by software with retention values in biopartioning micellar chromatography. The experimental results reveal that anti-inflammatory, antipyretic and analgesic effects are the main efficacy of honeysuckle, the antibiotic and antiviral effects take second place, effect of lowering blood pressure (BP), high blood fat and blood sugar is the weakest. Besides, with further relevant Matlab programming function, the probability of the components associated with different effects can be obtained by calculating the honeysuckle capacity factors, so as to identify which peak represents the active ingredient in the chromatogram and which is the main pharmacological action. This study confirmed that application of biopartioning micellar chromatography in screening active ingredients of traditional Chinese medicines is practicable. It paved the way for screening and analysis of the bioactive compounds in traditional Chinese medicines and may extend to the study of the interaction of the extract of traditional Chinese medicines with other biopolymers. This paper provides a model for rapid screening of active ingredients from traditional Chinese medicines ----honeysuckle. The screening and analyzing of the bioactive components in traditional Chinese medicines are very important not only for the quality control of the crude herb substances but also for elucidating the therapeutic mechanisms of traditional Chinese medicines, which is the key to modernize Chinese herbal medicine.

\section{EXPERIMENTAL}

Antibiotics and antiviral drugs: Ofloxacin, lomefloxacinhydrochloride, cefdinir, cefprozil, tetracycline, cefalexin, thiamphenicol, gatifloxacin, ciprofloxacin, ganciclovir, lamivudine, cefuroxime axetil, clindamycin phosphate for injection, clarithromycin sustained release tablet, amoxicillin, streptomycin sulphate, Zidovudine.

Antihypertensive drugs: Captopril, perindopril, propranolol hydrochloride, metoprolol tatrate, diltiazem hydrochloride, valsartan, imidapril, benazepril hydrochloride, pravastatin, metformin, atenolol, losartan potassium, alfuzos in hydrochloride, bisoprololfumarate, fluvastatin, prazosin hydrochloride, Simvastatin.

Antipyretic analgesics and antiinflammation drugs: Ibuprofen, aminopyrine, nimesulide, tramadol hydrochloride, methylprednisolone sodium succinate, benorilate, celecoxib.

All the drugs were donated by the pharmaceutical and pharmaceutical chemistry laboratories of West China School of Pharmacy, Sichuan University (Chengdu, China). Chlorogenic acid (purity $99.9 \%$ ) was purchased from the Institute for the Control of Pharmaceutical and Biological Products of China (Chengdu, China). Besides, the Flos Lonicerae Japonicae was purchased from Changchunteng Pharmacy (Chengdu, China).

\section{General procedure}

Preparation of honeysuckle samples: Extracting solution of honeysuckle was prepared using three kinds of methods to get as much ingredient as possible.

Reflux extraction: $10 \mathrm{~g}$ of sample was placed into a 250 $\mathrm{mL}$ round bottomed flask and $120 \mathrm{~mL}$ of $75 \%$ ethanol was added and then decocted to boil keeping for $90 \mathrm{~min}$ with $80{ }^{\circ} \mathrm{C}$ thermostat water bath. The process was repeated twice. The combined alcoholic extract was filtered through two layers filter paper, then concentrated under the reduced pressure with a rotary evaporator.

Ultrasonic extraction: Ultrasonic-assisted extraction was performed in a sonication cleaning bath operated at a frequency of $40 \mathrm{kHz}$ and an ultrasonic input power of $250 \mathrm{~W}$ with a volume of $4 \mathrm{~L}$. The available range for extraction temperature was from 0 to $110^{\circ} \mathrm{C}$. Extraction process was carried out as follows: $10 \mathrm{~g}$ of honeysuckle powder was placed in a $250 \mathrm{~mL}$ Erlenmeyer flask and mixed with $120 \mathrm{~mL}$ of $75 \%$ aqueous ethanol solution, after which the flask was placed in the constant temperature bath at $60{ }^{\circ} \mathrm{C}$ for $5-6 \mathrm{~h}$, then extraction carried out for $45 \mathrm{~min}$. Upon extraction, the mixture was filtered through a Buchner funnel under vacuum, after which the filtrates were collected in a volumetric flask. the filtrate was concentrated with a rotary evaporator evaporation.

Water decoction: $10 \mathrm{~g}$ of dried honeysuckle powder was weighted accurately to a beaker, $120 \mathrm{~mL}$ deionized water was added,put the beaker on the electric furnace, then decocted to boil keeping for $1 \mathrm{~h}$. The process was repeated twice. The combined water extract was filtered through two layers filter paper, then concentrated under the reduced pressure with a rotary evaporator.

All the above extracts were then centrifuged at 12,000 rpm for $3 \mathrm{~min}$. The supernatant was filtered through a 0.45 $\mu \mathrm{m}$ nylon filter then stored in the refrigerator at $4{ }^{\circ} \mathrm{C}$.

Preparation of solutions: The mobile phase consisted of $0.04 \mathrm{~mol} / \mathrm{L}$ polyoxyethylene (23) laurylether (Brij35, Acros, $\mathrm{NJ}$, USA) with $0.01 \mathrm{~mol} / \mathrm{L}$ sodium dihydrogenphosphate (analytical-reagent grade, Kelong, Chengdu, China) and was adjusted to $\mathrm{pH} 7.4$, which is the plasmatic $\mathrm{pH}$ value by sodium hydroxide. In order to reproduce the osmotic pressure of biological fluids, Sodium chloride $(9.20 \mathrm{~g} / \mathrm{L}$, analytical-reagent grade, Kelong, Chengdu, China) was added to the micellar mobile phase. Sodium chloride concentration was close to physiological concentration of biological fluids.

Stock standard solutions were prepared by dissolving 10 $\mathrm{mg}$ of the compound in $10 \mathrm{~mL}$ of mobile phase solution or deionized water.

Detection method: The retention of drugs was measured using a chromatograph with an LC-6A pump, an LC-6A UV detector and a CTO-6A column thermostat (Shimadzu, Japan). Data was collected and processed on a Alltech computer installed with chromstation software. The solutions were injected 
into the chromatograph through a Rheodyne valve (Cotati, CA, USA) with a $20 \mu \mathrm{L}$ loop. The HPLC column was a Diamonsil TM C18 column $(5 \mu \mathrm{m}, 4.6 \times 250 \mathrm{~mm}$ i.d. $)$ with a phenomenex security Guard TMC 18 guard cartridge. The UV detection of honeysuckle extracts was monitored from 210 to $300 \mathrm{~nm}$. Water was from a Millipore (Billerica, MA, USA) synergy TM 185 system and was degassed before HPLC. The mobile phases injected into the chromatograph was filtered through $0.45 \mu \mathrm{m}$ micro porous membrane. The mobile phase flow rate was $1 \mathrm{~mL} / \mathrm{min}$. All the assays were carried out at $37{ }^{\circ} \mathrm{C}$ for simulating human body temperature. The retention data in biopartioning micellar chromatography were calculated as capacity factors, $\mathrm{k}_{\mathrm{BMC}}=\left(\mathrm{t}_{\mathrm{r}}-\mathrm{t}_{0}\right) / \mathrm{t}_{0}$, where $\mathrm{t}_{\mathrm{r}}$ is the retention time of the test compound and $t_{0}$ is the column dead time, which is the first fluctuation of baseline, determined by injecting water. The $\mathrm{k}_{\mathrm{BMC}}$ values used in this study were the average value of triplicate. The retention data were highly reproducible.

\section{RESULTS AND DISCUSSION}

Screening and analysis data: Besides chlorogenic acid, flos lonicerae may also contain many different unknown components with different physicochemical properties. In this study, components of honeysuckle were extracted as much as possible by different methods, as we commented previously. Detect different ingredients in 200-400 nm ultraviolet absorption wavelength range. Considering the random error and systematic error, such as concentration of mobile phase, experimental conditions and the tiny difference of temperature, etc. The time of pure water, chlorogenic acid reference substance and different acid, alkaline and amphoteric drugs (benazepril, propranolol, prazosin) were investigated and interdays and intra-days precision of their retention values were all less than $2 \%$, which indicate that repeatability is good for all the retention values tested. Therefore, the retention values of each peak in every honeysuckle chromatogram with a difference more than $3 \%$ are considered different ingredients. Table-1 shows the biopartioning micellar chromatography retention data of the honeysuckle extract, which were calculated as capacity factors, $\mathrm{k}_{\mathrm{BMC}}=\left(\mathrm{t}_{\mathrm{r}}-\mathrm{t}_{0}\right) / \mathrm{t}_{0}$.

Table-2 shows the calculation results of drugs with similar pharmacological effects of honeysuckle.

Chlorogenic acid (CA) and flavonoids represented by galuteolin are the major bioactive constituent in honeysuckle ${ }^{26}$. The maximum absorption wavelength of CA is $324-327 \mathrm{~nm}^{27-29}$. Literature reported at wavelength of $355 \mathrm{~nm}$, three main ingredients (CA, galuteolin and hyperosid) in honeysuckle show strong UV absorption ${ }^{30}$. Simultaneous determination of $\mathrm{CA}$ and galuteolin in honeysuckle at $350 \mathrm{~nm}$ was reported by Zhang et al. ${ }^{31}$. Thus, chose the chromatogram with the minimum wavelength of $210 \mathrm{~nm}$, the highest wavelength (390

\begin{tabular}{|c|c|c|c|c|c|c|c|c|c|}
\hline \multicolumn{10}{|c|}{$\begin{array}{c}\text { TABLE-1 } \\
\text { CAPACITY FACTOR OF HONEYSUCKLE EXTRACT- } \text { kMC }_{\text {BMC }} \text { OF HONEYSUCKLE EXTRACT IN BMC SYSTEM }\end{array}$} \\
\hline $\mathrm{k}_{1}$ & $\mathrm{k}_{2}$ & $\mathrm{k}_{3}$ & $\mathrm{k}_{4}$ & $\mathrm{k}_{5}$ & $\mathrm{k}_{6}$ & $\mathrm{k}_{7}$ & $\mathrm{~K}_{8}$ & $\mathrm{k}_{9}$ & $\mathrm{k}_{10}$ \\
\hline 0.005 & 0.051 & 0.200 & 0.210 & 0.272 & 0.277 & 0.527 & 0.680 & 0.718 & 3. 008 \\
\hline $\mathrm{k}_{11}$ & $\mathrm{k}_{12}$ & $\mathrm{k}_{13}$ & $\mathrm{k}_{14}$ & $\mathrm{k}_{15}$ & $\mathrm{k}_{16}$ & $\mathrm{k}_{17}$ & $\mathrm{k}_{18}$ & $\mathrm{k}_{19}$ & $\mathrm{k}_{20}$ \\
\hline 2.420 & 3.108 & 3.188 & 3.231 & 3.282 & 3.355 & 3.359 & 4.273 & 4.353 & 2.23 \\
\hline $\mathrm{k}_{21}$ & $\mathrm{k}_{22}$ & $\mathrm{k}_{23}$ & $\mathrm{k}_{24}$ & $\mathrm{k}_{25}$ & $\mathrm{k}_{26}$ & $\mathrm{k}_{27}$ & $\mathrm{~K}_{28}$ & $\mathrm{k}_{29}$ & $\mathrm{k}_{30}$ \\
\hline 2.420 & 3.108 & 3.188 & 3.231 & 3.282 & 3.355 & 3.359 & 4.273 & 4.353 & 4.562 \\
\hline $\mathrm{k}_{31}$ & $\mathrm{k}_{32}$ & $\mathrm{k}_{33}$ & $\mathrm{k}_{34}$ & $\mathrm{k}_{35}$ & $\mathrm{k}_{36}$ & $\mathrm{k}_{37}$ & $\mathrm{~K}_{38}$ & $\mathrm{k}_{39}$ & $\mathrm{k}_{40}$ \\
\hline 4.583 & 4.665 & 4.909 & 5.610 & 5.956 & 7.324 & 7.749 & 8.242 & 8.828 & 9.202 \\
\hline $\mathrm{k}_{41}$ & $\mathrm{k}_{42}$ & $\mathrm{k}_{43}$ & $\mathrm{k}_{44}$ & $\mathrm{k}_{45}$ & $\mathrm{k}_{46}$ & - & - & - & - \\
\hline 9.393 & 10.152 & 10.938 & 12.20 & 13.214 & 14.253 & - & - & - & - \\
\hline
\end{tabular}

\begin{tabular}{|c|c|c|c|c|c|}
\hline \multicolumn{6}{|c|}{$\begin{array}{c}\text { TABLE-2 } \\
\text { CAPACITY FACTOR OF THE RELATED WESTERN MEDICINE }\end{array}$} \\
\hline Antibiotics and antiviral drugs & $\mathrm{k}_{1}$ & Antihypertensive drugs & $\mathrm{k}_{2}$ & $\begin{array}{l}\text { Antipyretic analgesicsand } \\
\text { antiinflammation drugs }\end{array}$ & $\mathrm{k}_{3}$ \\
\hline Ofloxacin & 2.082 & Captopril & 10.89 & Ibuprofen & 1.515 \\
\hline $\begin{array}{l}\text { Lomefloxacin } \\
\text { Hydrochloride }\end{array}$ & 0.565 & Perindopril & 1.525 & Aminopyrine & 3.740 \\
\hline Cefdinir & 0.924 & Propranolole hydrochloride & 17.56 & Nimesulide & 1.115 \\
\hline Cefprozil & 0.544 & Metoprolol tartrate & 2.659 & Tramadol hydrochloride & 7.318 \\
\hline Cefalexin & 0.415 & Melbine & 0.384 & Methylprednisolone sodium succinate & 7.814 \\
\hline Tetracycline & 1.486 & Diltiazem hydrochloride & 3.050 & Benorilate & 1.231 \\
\hline Thiamphenicol & 2.483 & Valsartan & 0.266 & Celecoxib & 1.879 \\
\hline Gatifloxacin & 1.047 & Imidapril & 3.384 & & \\
\hline Ciprofloxacin & 1.242 & Benazepril hydrochloride & 2.060 & & \\
\hline Ganciclovir & 0.470 & Pravastatin & 4.483 & & \\
\hline Acyclovir & 0.620 & Atenolol & 0.591 & & \\
\hline Zidovudine & 2.271 & Losartan potassium & 15.461 & & \\
\hline Lamivudine & 0.881 & Alfuzosin hydrochloride & 13.089 & & \\
\hline Cefuroxime axetil & 19.94 & Bisoprolol fumarate & 6.664 & & \\
\hline Clindamycin phosphate for injection & 1.828 & Fluvastatin & 16.063 & & \\
\hline Clarithromycin sustained release tablet & 0.457 & Prazosin hydrochloride & 18.516 & & \\
\hline Streptomycin sulphate & 0.557 & Simvastatin & 10.513 & & \\
\hline Amoxicillin & 1.085 & & & & \\
\hline
\end{tabular}


$\mathrm{nm})$ and maximum absorption wavelength (254, 325 and 350 $\mathrm{nm}$ ) of the principal components to show the components of honeysuckle extracts detected at different wavelength representatively (Figs. 1-5).

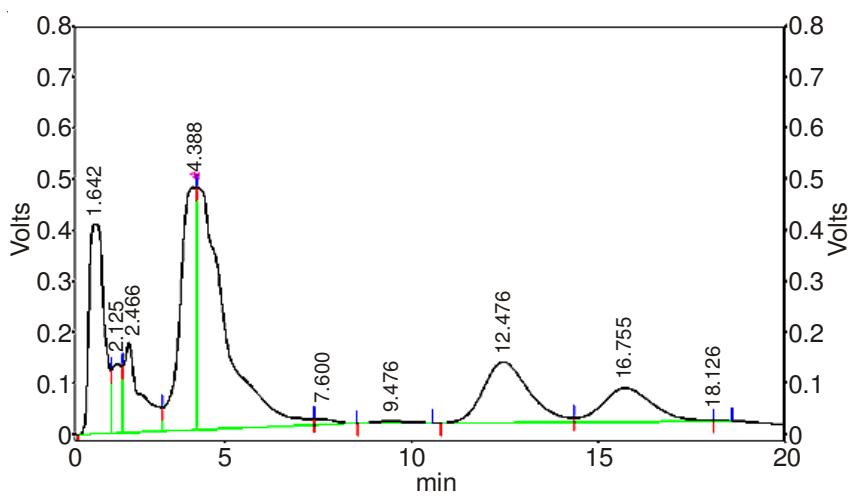

Fig. 1. Decoction of flos lonicerae peaks $(210 \mathrm{~nm})$

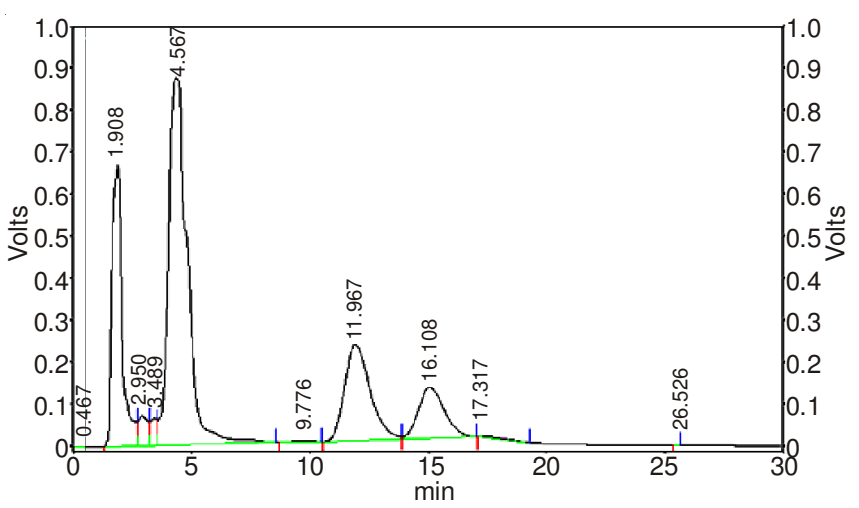

Fig. 2. Decoction of flos lonicerae peaks (254)

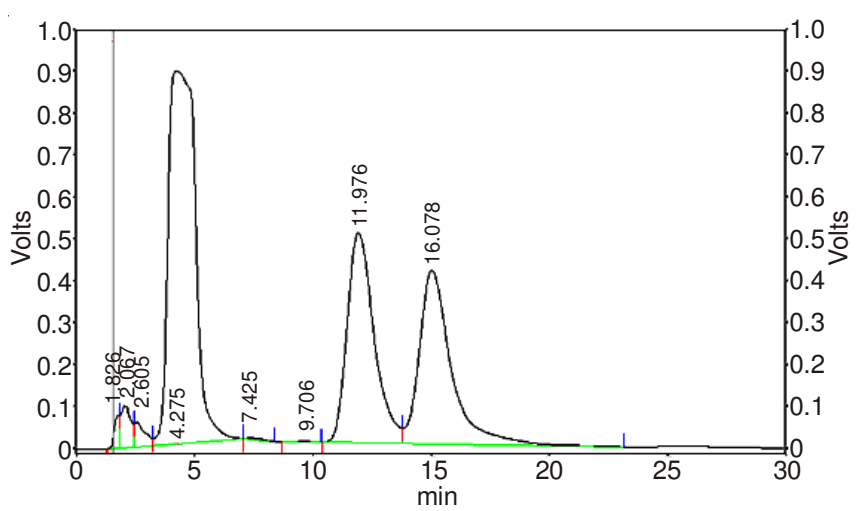

Fig. 3. Decoction of flos lonicerae peaks (325)

Software and data processing: SPSS 15 for windows program, Matlab 6 of the Math Works Incorporation and Excel 2003 of Microsoft office software were used to accomplish the statistical analysis.

Analysis of variance method (ANOVA): Analysis of variance, also known as ANOVA, is perhaps the most power

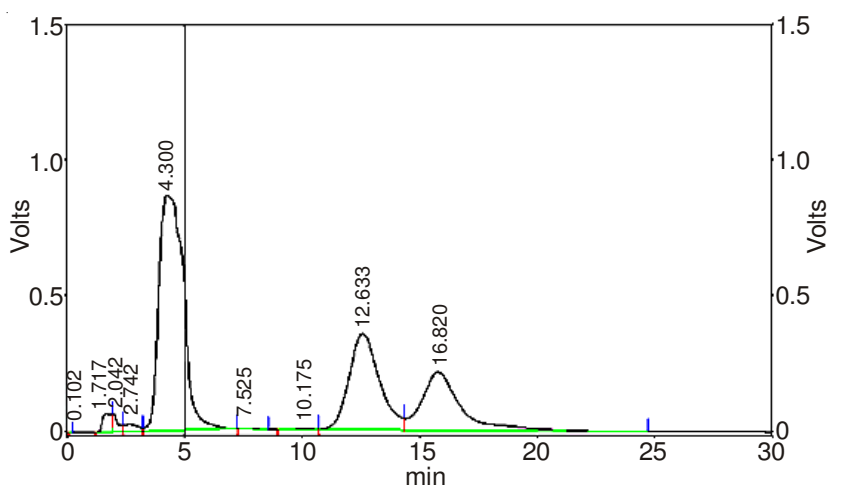

Fig. 4. Decoction of flos lonicerae peaks $(350 \mathrm{~nm})$

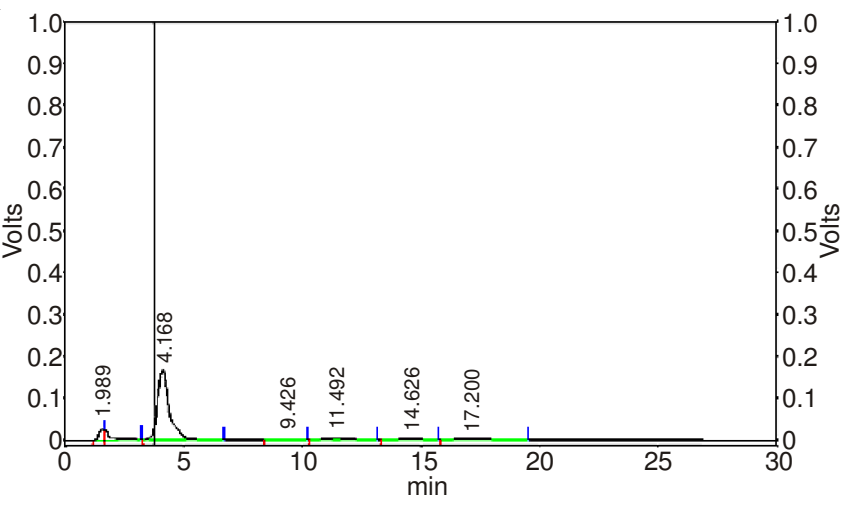

Fig. 5. Decoction of flos lonicerae peaks (390)

ful statistical tool. ANOVA is a general method of analyzing data from designed experiments, whose objective is to compare two or more group means. The analysis of variance is used widely in the biological, social and physical sciences.

Table- 3 contains the results of the statistical analysis through variance analysis.it shows that significance level is $\alpha=0.05, \mathrm{P}=0.008<0.05, \mathrm{~F}_{0.95}(3,85)=3.3$, because $\mathrm{F}=4.16$ $>3.3$, thus, on the significant level $(\alpha=0.05)$, levels of experimental data between groups have significant differences. We can then determine there are differences among the capacity factors of honeysuckle extract and related drugs.

Make scatter plot with the absolute values of the differences between the RSD of honeysuckle extract and the three kind of chemical drugs respectively, as shown in the Fig. 6. If the ordinate is more close to zero that indicate pharmacological effect of the drug is more similar with the component of honeysuckle extract. From Fig. 6, we can preliminary draw a conclusion that honeysuckle mainly shows antipyretic, analgesic and antiinflammatory effects.

Compare the mean of the capacity factors between honeysuckle extract and the three kind of related drugs respectively, through the analysis, we got the following conclusions shown in Table-4. The behavior in biopartioning micellar chromatography system of honeysuckle extract is more similar with antipyretic analgesic antiinflammatory drugs', which is

\begin{tabular}{|c|c|c|c|c|c|}
\hline \multicolumn{6}{|c|}{$\begin{array}{c}\text { TABLE-3 } \\
\text { ANALYSIS OF VARIANCE }\end{array}$} \\
\hline Error sources & Square sum & Freedom degree & Mean square & $\mathrm{F}$ & Sig. \\
\hline$A_{\text {between groups }}$ & $S_{A}=260.590$ & $\mathrm{f}_{\mathrm{A}}=3$ & $V_{A}=86.863$ & $F=4.16$ & 0.008 \\
\hline $\mathrm{e}_{\text {within groups }}$ & $S_{e}=1774.841$ & $\mathrm{f}_{\mathrm{e}}=85$ & $V_{e}=20.880$ & - & - \\
\hline Total & $\mathrm{S}_{\mathrm{T}}=2035.431$ & $\mathrm{f}_{\mathrm{T}}=88$ & - & - & - \\
\hline
\end{tabular}


TABLE-4

MULTIPLE VARIANCE COMPARISON BETWEEN HONEYSUCKLE AND RELATED CHEMICAL DRUGS

\begin{tabular}{ccccccc}
\hline (I) $\mathrm{x}$ & $(\mathrm{J}) \mathrm{x}$ & Mean Difference $(\mathrm{I}-\mathrm{J})$ & Std. Error & Sig. & 95 \% Confidence Interval & \\
\hline \multirow{3}{*}{1} & & Lower Bound & Upper Bound & Lower Bound & Upper Bound & Lower Bound \\
& 2 & 1.932 & 1.267 & 0.511 & -1.681 & 5.545 \\
& 3 & -3.387 & 1.293 & 0.084 & -7.076 & 0.302 \\
& 4 & 0.577 & 1.851 & 0.992 & -4.704 & 5.857 \\
\hline
\end{tabular}

1 In the (I) $x$ represents honeysuckle extract; $2,3,4$ in the (J) x represent antibacterial antiviral drugs, antihypertensive drugs, antipyretic analgesic anti-inflammatory drug respectively

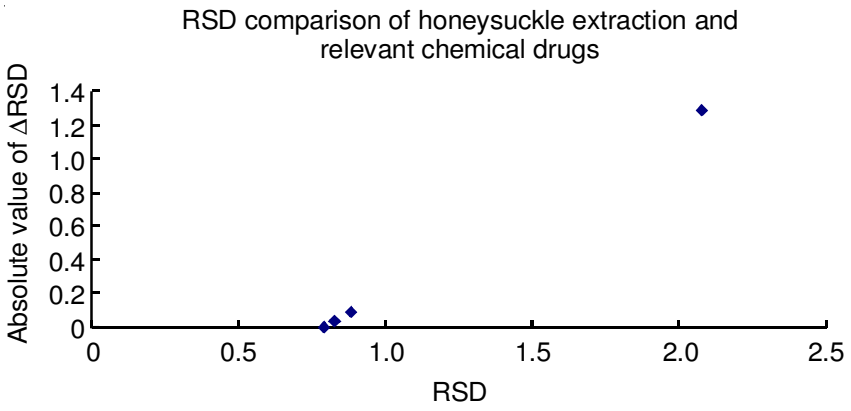

\begin{tabular}{|c|c|c|c|c|}
\hline Item & $\begin{array}{c}1- \\
\text { Honeysuckle } \\
\text { extract }\end{array}$ & $\begin{array}{c}\text { 2-Antipyretic } \\
\text { analgesics } \\
\text { and anti- } \\
\text { inflammation } \\
\text { drugs }\end{array}$ & $\begin{array}{c}\text { 3-Antihy- } \\
\text { pertensive } \\
\text { drugs }\end{array}$ & $\begin{array}{c}\text { 4-Antibiotic } \\
\text { sand } \\
\text { Antiviral } \\
\text { drugs }\end{array}$ \\
\hline RSD & 0.793 & 0.826 & 0.882 & 2.076 \\
\hline $\mid \Delta \mathrm{RSDI}$ & 0 & 0.033 & 0.089 & 1.283 \\
\hline
\end{tabular}

$|\triangle \mathrm{RSD}|$ represents the absolute value of the subtraction results between honeysuckle and each kind of drugs, respectively. The point on the Fig. 1 from left to right represent 1-honeysuckle extract, 2-antipyretic analgesics and antiinflammation drugs, 3-antihypertensive drugs, 4antibiotics and antiviral drugs, respectively

Fig. 6. RSD comparison of honeysuckle extraction and relevant chemical drugs

consistent with the initial judgment. However, the result is also not so precise while the sig. is bigger than 0.05 .

Since the above results are just simply preliminary judgment, in order to achieve a more reliable result, a detailed statistical model was established to make further analysis.

Programming method: Matlab 6 of the Math Works Incorporation was used to perform the statistical analysis of programming.

Pharmacological ingredients were classified according to the capacity factors, firstly, take advantage of the drug data to establish mathematical model to simulate the probability of each factor belong to corresponding category. Set up a collection for the capacity factor of a kind of drugs as $\left\{a_{1}, a_{2}, . ., a_{n}\right\}, b$ is for unspecified capacity factor. we can assume that for each known factor corresponding to an average $\left(\mathrm{a}_{\mathrm{i}}\right)$, there's a normal distribution $\mathrm{N}\left(\mathrm{a}_{\mathrm{i}}, \sigma_{\mathrm{i}}^{2}\right)$ with a standard $\sigma$ (to be provided). Probability prediction function of all experiment data can be obtained by adding up probability density function of all the distribution, written simply as $\mathrm{f}$.

$f(x)=\frac{1}{n} \sum_{i=1}^{n} \frac{1}{\sqrt{2 \pi \sigma_{i}}} e^{-\frac{\left(x-a_{i}\right)^{2}}{2 \sigma_{i}^{2}}}$ where the $\frac{1}{n}$ is to ensure the integration of the entire function $\mathrm{f}(\mathrm{x})$ equals to 1 . To estimate the probability of capacity factor b belongs to which category of drugs, we only need to observe the condition of the function $f(x)$ in the vicinity of $b$ value. Therefore, the integral value $p$ of $f(x)$ in the interval $P[b-r / 2, b+r / 2]$ is considered, where $b$ is the midpoint between the width of $r$. Three different integration $\mathrm{p}_{1}, \mathrm{p}_{2}, \mathrm{p}_{3}$ can be concluded by using the three kinds of chemical drugs data. Moreover, compare the three values $\left(\mathrm{p}_{1}, \mathrm{p}_{2}, \mathrm{p}_{3}\right)$, then we can see which is the most possible category that the capacity factor $b$ belongs to.

The above process can be realized by programming with Matlab. In the process of actual calculation, we assume that all $\sigma_{i}$ get the same value $\sigma$. Observing a set of data and the experimental result,we can get that $\sigma=0.12, \mathrm{r}=0.015$. In addition, if for a certain factor, the three integral values $\mathrm{p}_{1}, \mathrm{p}_{2}$, $\mathrm{p}_{3}$ are less than $5 \%$, then we don't think this factor is likely to belong to any kind of the three known drugs. The specific calculation results all keep three decimal places (Teble-5).

Because the extraction methods are mainly for chlorogenic acid and flavonoids, which are considered as the principal components, component of flos lonicerae may haven't been fully extracted. Briji35 is a kind of nonionic surfactant, which is lipophilic and small polar with strong eluting ability. Liposoluble constituents in Flos lonicerae extracts may be eluted in a short time. The data is far from comprehensive, since the category and quantity of the experimental drugs are limited, the results with mathematical statistical analysis are less precise and perfect. However, this study provides a creative idea, which is combining efficacy of chemical drugs and Chinese traditional herbs with metabolism model in vitro and mathematical statistical analysis to predict and screen the bioactive constituents.

A new approach for assigning bioactivity to individual components in extracts from honeysuckle (Lonicera japonica) is demonstrated. We can get ingredients with different efficacy by screening active component of Chinese herbs and prescription through predicting model in vitro, thereby, further deduce the effective part of herbs. Separate effective component and verify the associated pharmacological activity purposefully with these components, avoiding interference of a large number of inactive ingredients, instead of a lot of isolation and purification for traditional Chinese medicines, provide a new, fast and effective method for material foundation of efficacy of Chinese herbs and compound prescription of Chinese medicine.

\section{Conclusion}

The aim of this paper is to provide a method to predict and identify active ingredients in honeysuckle by biopartioning micellar chromatography. It reflects the interactions of drugs and cell membrane to some extent, the retention behavior of 
TABLE-5

CAPACITY FACTOR OF EXTRACT OF FLOS LONICERAE AND ITS RELATED CHEMICAL DRUGS PROBABILITY

\begin{tabular}{|c|c|c|c|c|c|c|}
\hline Capacity factor $\mathrm{k}$ & $\begin{array}{l}\text { Most possible } \\
\text { category }\end{array}$ & $\begin{array}{c}\text { Relative } \\
\text { probability }\end{array}$ & $\begin{array}{l}\text { Second possible } \\
\text { category }\end{array}$ & $\begin{array}{c}\text { Relative } \\
\text { probability }\end{array}$ & $\begin{array}{l}\text { Least possible } \\
\text { category }\end{array}$ & $\begin{array}{c}\text { Relative } \\
\text { probability }\end{array}$ \\
\hline 0.005 & 2 & 0.020 & 1 & 0.0008 & 3 & $1.29 \mathrm{E}-19$ \\
\hline 0.051 & 2 & 0.043 & 1 & 0.003 & 3 & $4.26 \mathrm{E}-18$ \\
\hline 0.104 & 2 & 0.091 & 1 & 0.011 & 3 & $1.84 \mathrm{E}-16$ \\
\hline 0.200 & 2 & 0.229 & 1 & 0.078 & 3 & $1.15 \mathrm{E}-13$ \\
\hline 0.210 & 2 & 0.244 & 1 & 0.092 & 3 & $2.13 \mathrm{E}-13$ \\
\hline 0.272 & 2 & 0.327 & 1 & 0.232 & 3 & $9.25 \mathrm{E}-12$ \\
\hline 0.277 & 2 & 0.332 & 1 & 0.247 & 3 & $1.23 \mathrm{E}-11$ \\
\hline 0.527 & 1 & 1.116 & 2 & 0.285 & 3 & 2.92E-06 \\
\hline 0.680 & 1 & 0.646 & 2 & 0.158 & 3 & 0.0007 \\
\hline 0.718 & 1 & 0.524 & 2 & 0.116 & 3 & 0.002 \\
\hline 0.778 & 1 & 0.430 & 2 & 0.059 & 3 & 0.010 \\
\hline 0.973 & 1 & 0.599 & 3 & 0.283 & 2 & 0.001 \\
\hline 1.362 & 3 & 0.529 & 1 & 0.240 & 2 & 0.078 \\
\hline 1.473 & 3 & 0.515 & 1 & 0.216 & 2 & 0.178 \\
\hline 1.512 & 3 & 0.511 & 1 & 0.201 & 2 & 0.194 \\
\hline 1.525 & 3 & 0.504 & 2 & 0.195 & 1 & 0.195 \\
\hline 1.542 & 3 & 0.490 & 2 & 0.194 & 1 & 0.185 \\
\hline 1.745 & 3 & 0.331 & 1 & 0.167 & 2 & 0.043 \\
\hline 1.789 & 3 & 0.394 & 1 & 0.192 & 2 & 0.033 \\
\hline 2.034 & 1 & 0.239 & 3 & 0.207 & 2 & 0.191 \\
\hline 2.230 & 1 & 0.281 & 2 & 0.072 & 3 & 0.007 \\
\hline 2.420 & 1 & 0.250 & 2 & 0.029 & 3 & $1.83 \mathrm{E}-05$ \\
\hline 3.108 & 2 & 0.188 & 3 & $4.55 \mathrm{E}-07$ & 1 & $2.39 \mathrm{E}-07$ \\
\hline 3.188 & 2 & 0.153 & 3 & $1.20 \mathrm{E}-05$ & 1 & $6.04 \mathrm{E}-09$ \\
\hline 3.231 & 2 & 0.150 & 3 & $5.90 \mathrm{E}-05$ & 1 & $6.83 \mathrm{E}-10$ \\
\hline 3.282 & 2 & 0.166 & 3 & 0.0003 & 1 & $4.56 \mathrm{E}-11$ \\
\hline 3.355 & 2 & 0.197 & 3 & 0.003 & 1 & $6.61 \mathrm{E}-13$ \\
\hline 3.359 & 2 & 0.198 & 3 & 0.003 & 1 & $5.12 \mathrm{E}-13$ \\
\hline 4.273 & 2 & 0.042 & 3 & $2.56 \mathrm{E}-05$ & 1 & $1.05 \mathrm{E}-49$ \\
\hline 4.353 & 2 & 0.108 & 3 & $1.08 \mathrm{E}-06$ & 1 & $4.25 \mathrm{E}-54$ \\
\hline 4.562 & 2 & 0.158 & 3 & $3.29 \mathrm{E}-11$ & 1 & $1.53 \mathrm{E}-66$ \\
\hline 4.583 & 2 & 0.138 & 3 & $9.71 \mathrm{E}-12$ & 1 & $7.10 \mathrm{E}-68$ \\
\hline 4.665 & 2 & 0.062 & 3 & $6.48 \mathrm{E}-14$ & 1 & $3.79 \mathrm{E}-73$ \\
\hline 4.909 & 2 & 0.0004 & 3 & $1.30 \mathrm{E}-21$ & 1 & 4.23E-90 \\
\hline 5.610 & 2 & $3.77 \mathrm{E}-18$ & 3 & $5.42 \mathrm{E}-45$ & 1 & $9.78 \mathrm{E}-149$ \\
\hline 5.956 & 2 & $5.724 \mathrm{E}-09$ & 3 & $5.56 \mathrm{E}-29$ & 1 & $3.64 \mathrm{E}-183$ \\
\hline 7.324 & 3 & 0.474 & 2 & 5.34E-08 & 1 & 0 \\
\hline 7.749 & 3 & 0.411 & 2 & $3.64 \mathrm{E}-19$ & 1 & 0 \\
\hline 8.241 & 3 & 0.001 & 2 & $6.22 \mathrm{E}-39$ & 1 & 0 \\
\hline 8.828 & 3 & $1.47 \mathrm{E}-16$ & 2 & $3.41 \mathrm{E}-44$ & 1 & 0 \\
\hline 9.202 & 2 & $2.39 \mathrm{E}-27$ & 3 & $4.58 \mathrm{E}-30$ & 1 & 0 \\
\hline 9.393 & 2 & $2.47 \mathrm{E}-20$ & 3 & $1.26 \mathrm{E}-38$ & 1 & 0 \\
\hline 10.152 & 2 & 0.002 & 3 & $2.05 \mathrm{E}-83$ & 1 & 0 \\
\hline 10.938 & 2 & 0.179 & 3 & $4.1 \mathrm{E}-148$ & 1 & 0 \\
\hline 12.197 & 2 & $1.92 \mathrm{E}-13$ & 3 & $1.9 \mathrm{E}-290$ & 1 & 0 \\
\hline 13.214 & 2 & 0.115 & 2 & 0 & 1 & 0 \\
\hline 14.253 & 2 & $8.30 \mathrm{E}-22$ & 2 & 0 & 1 & 0 \\
\hline
\end{tabular}

1. Represents antibacterial antiviral drugs, 2. represents blood pressure (fat) blood sugar medicine; 3. represents antipyretic analgesic antiinflammatory drugs; the bold Numbers to the corresponding capacity factor k probably do not belong to any of the three kinds of medicine

the active ingredients in biopartioning micellar chromatography system has significant correlation with pharmacological activities. Screening traditional Chinese medicines active ingredients through combining the related biological activity parameters of the curative effect of chemical drugs, provide a scientific basis for the application of traditional Chinese medicines in the future. This study provides key information for traditional Chinese medicines quality control and more reflective of the quality control of the efficacy of the traditional Chinese medicines. Screening of effective components of Chinese herbal medicine has a huge promotion for study on effects of traditional Chinese medicines compounds, conducive to the development and modernization of traditional Chinese medicines. However, the experimental data is still scarce, further studies are still necessary to get a more precise model.

\section{ACKNOWLEDGEMENTS}

The authors are thankful to Cong Wu (School of Mathematics, University of Southern California) and Linyu Yang (School of mathematics, Southwest Jiaotong University, Chengdu, China) for valuable discussion and the statistical help. 


\section{REFERENCES}

1. Z.G. He, J. Sun, X. Wu, R. Lu, J.F. Liu and Y.J. Wang, Curr. Drug Metab., 9, 152 (2008).

2. L. Escuder-Gilabert, S. Sagrado, R.M. Villanueva-Camanas and M.J. MedinaHernandez, Anal. Chem., 70, 28 (1998).

3. M. Cuenca-Benito, S. Sagrado, R.M. Villanueva-Camanas and M.J. Medina-Hernandez, J. Chromatogr. A, 814, 121 (1998).

4. J.M. Sanchis-Mallols, R.M. Villanueva-Camanas, S. Sagrado and M.J. Medina-Hernandez, Chromatographia, 46, 605 (1997).

5. M. Molero-Monfort, S. Sagrado, R.M. Villanueva-Camanas and M.J. Medina-Hernandez, Biomed. Chromatogr., 13, 394 (1999).

6. C. Quinones-Torrelo, S. Sagrado, R.M. Villanueva-Camanas and M.J. Medina-Hernandez, J. Med. Chem., 42, 3154 (1999).

7. Y. Martin-Biosca, M. Molero-Monfort, S. Sagrado, R.M. VillanuevaCamanas and M.J. Medina-Hernandez, Biomed. Chromatogr., 13, 478 (1999).

8. L. Escuder-Gilabert, S. Sagrado, R.M. Villanueva-Camanas and M.J. Medina-Hernandez, J. Chromatogr. B: Analyt. Technol. Biomed. Life Sci., 740, 59 (2000).

9. J.J. Martýìnez-Pla, S. Sagrado, R.M. Villanueva-Camañas and M.J. Medina-Hernández, J. Chromatogr. B: Biomed. Sci. Appl., 757, 89 (2001).

10. M. Molero-Monfort, Y. Martin-Biosca, S. Sagrado, R.M. VillanuevaCamanas and M.J. Medina-Hernandez, J. Chromatogr. A, 870, 1 (2000).

11. M. Molero-Monfort, L. Escuder-Gilabert, R.M. Villanueva-Camañas, S. Sagrado and M.J. Medina-Hernández, J. Chromatogr. B: Biomed. Sci. Appl., 753, 225 (2001).

12. M. Hadjmohammadi and M. Salary, J. Chromatogr. B Analyt. Technol. Biomed. Life Sci., 912, 50 (2013).

13. S.-R. Wang, Y. Chen, L.-P. Wu, W.-J. Miao, M.-J. Xiong, C. Chen, Z.R. Zhong and L.-M. Ye, J. Pharm. Biomed. Anal., 46, 243 (2008).
14. S.R. Wang, C. Chen, M.J. Xiong, L.P. Wu and L.M. Ye, J. Chromatogr. Sci., 48, 134 (2010).

15. L. Wu, L. Ye, C. Chen, J. Wu and Y. Chen, Biomed. Chromatogr., 22, 606 (2008).

16. Y. Chen, Li-ping Wu, Cong Chen, Li-ming Ye, Biomed. Chromatogr., 24, 195 (2010)

17. Pharmacopoeia Commission of People's Republic of China, Pharmacopoeia of People's Republic of China, The Chemical Industry Press, Beijing (2005).

18. W.C. Chang and F.L. Hsu, Prostaglandins Leukot. Essent. Fatty Acids, 45, 307 (1992).

19. H. Hemmerle, H.J. Burger, P. Below, G. Schubert, R. Rippel, P.W. Schindler, E. Paulus and A.W. Herling, J. Med. Chem., 40, 137 (1997).

20. F. Pellati, S. Benvenuti, L. Magro, M. Melegari and F. Soragni, J. Pharm. Biomed. Anal., 35, 289 (2004).

21. A.S. Moreira, V. Spitzer, E.E.S. Schapoval and E.P. Schenkel, Phytother. Res., 14, 638 (2000).

22. T. Nakamura, Y. Nakazawa, S. Onizuka, Saori Satoh, A. Chiba, K. Sekihashi, A. Miura, N. Yasugahira and Y.F. Sasaki, Mutat. Res. Genet. Toxicol. Environ. Mutagen., 388, 7 (1997).

23. Y.F. Sasaki, A. Chiba, M. Murakami, K. Sekihashi, M. Tanaka, M. Takahoko, S. Moribayashi, C. Kudou, Y. Hara, Y. Nakazawa, T. Nakamura and S. Onizuka, Mutat. Res. Genet. Toxicol. Environ. Mutagen., 371, 203 (1996).

24. P.J. Houghton, Z. Boxu and Z. Xisheng, Phytother. Res., 73, 84 (1993).

25. S.Y. Kim, J.H. Kim, S.K. Kim, M.J. Oh and M.Y. Jung, J. Am. Oil Chem. Soc., 71, 633 (1994).

26. H. Xin, J. Feng, R.-M. Cheng and N. Xin, Chin. J. Exp. Trad. Med. Formulae, (2011)

27. F. Liao and X. Yao, J. Jiangxi Chem. Ind., 4, 43 (2011).

28. L. Wu and Z. Zhang, J. Food Sci., 26, 130 (2005).

29. Y. Wei, X. Liu and J. He, J. Shandong Inst. Light Ind., 4, 26 (2007).

30. P. Li, H. Jin and J. Jia, J. Tianjin Medical J., 37, 519 (2009).

31. Y. Zhang, J. Li, T. Chen and F. Li, J. Tianjin Univ. Tradit. Chin. Med., 30, 107 (2011). 